569 Supporting Information for

\title{
570 Thunderstorms increase mercury wet deposition
}

571 Christopher D. Holmes, Nishanth P. Krishnamurthy, Jane M. Caffrey, William M. Landing, Eric

572 S. Edgerton, Kenneth R. Knapp, Udaysankar S. Nair

573

574

575

576

577

578

579

580

\section{Contents}

Supplementary Text

4 Supplementary Figures

4 Supplementary Tables
Pages

S2-S3

S4-S6

S7-S8 


\section{Linear version of the statistical model}

To obtain a linear equation for least-squares fitting, the natural logarithm of Eq. (1) is

$$
\ln \left(c / c_{0}\right)=\ln \left(\beta_{0} / c_{0}\right)+\beta_{1} \ln \left(p / p_{0}\right)+\beta_{2^{\prime}} S+\beta_{3} V
$$
where $c_{0}=1 \mathrm{ng} \mathrm{L}^{-1}$ is a constant that makes the logarithm unitless, $\beta_{2},=\ln \left(1+\beta_{2}\right), \beta_{3} V$ quantifies the effect of radar and satellite variables $(V)$ listed in Table 2 , and other variables are defined in Section 2. This form is suitable for regression because $\ln \left(c / c_{0}\right)$ and $\ln \left(p / p_{0}\right)$ are approximately normally distributed, which can be seen in Fig. (2). Note that $\exp \left(\beta_{3} V\right) \approx\left(1+\beta_{3}\right)^{V}$, as given in the main text, because $\beta_{3} \ll 1$ for all choices of $V$ (see Table 2 ).

\section{Attribution of regional deposition to meteorological and chemical factors}

The observed deposition at each site is

$$
D=\sum_{i} c_{i} p_{i}
$$

where $c_{i}$ and $p_{i}$ are the observed concentration and precipitation depth, respectively, in individual precipitation events and the summation includes all $n$ events in each summer season (JuneAugust). The deposition can be predicted by

$$
\widehat{D}=\sum_{i} \hat{c}_{i} p_{i}=\beta_{0} \sum_{i}\left(\frac{p_{i}}{p_{0}}\right)^{\beta_{1}} p_{i}\left(1+\beta_{2} S_{i}\right)
$$

where $\hat{c}_{i}$ is the concentration predicted by Eq. (1) for a given precipitation depth, $p_{i}$, and storm type, $S_{i}$. To determine the hypothetical effects of independent changes in total precipitation, storm type, and precipitation depth distribution, suppose that the storm type is independent of precipitation depth, so

$$
\sum_{i}\left(\frac{p_{i}}{p_{0}}\right)^{\beta_{1}} p_{i}\left(1+\beta_{2} S_{i}\right) \approx\left(\sum_{i}\left(\frac{p_{i}}{p_{0}}\right)^{\beta_{1}} p_{i}\right)\left(\frac{1}{n} \sum_{i}\left(1+\beta_{2} S_{i}\right)\right)
$$

If $f=\frac{1}{n} \sum_{i} S_{i}$ is the fraction of the precipitation events are thunderstorms, then

$$
\frac{1}{n} \sum_{i}\left(1+\beta_{2} S_{i}\right)=1+f \beta_{2}
$$

Further, define the total summer precipitation as $p_{t}=\sum_{i} p_{i}$ so that Eq. (S3) becomes

$$
\widehat{D} \approx \beta_{0} p_{t}\left(1+f \beta_{2}\right)\left(\frac{\sum_{i}\left(\frac{p_{i}}{p_{0}}\right)^{\beta_{1}} p_{i}}{\sum_{i} p_{i}}\right)=\beta_{0} p_{t} \tilde{c}\left(1+f \beta_{2}\right),
$$

where

$$
\tilde{c}=\left(\sum_{i}\left(\frac{p_{i}}{p_{0}}\right)^{\beta_{1}} p_{i}\right)\left(\sum_{i} p_{i}\right)^{-1}
$$

is a characteristic dilution factor derived from a weighted average of the precipitation depths.

More simply, the characteristic dilution factor can be approximated as

$$
\tilde{c}=\left(\tilde{p} / p_{0}\right)^{\beta_{1}}
$$

where $\tilde{p}$ is a characteristic precipitation depth (e.g. mean or median). We use the mean for $\tilde{p}$. The characteristic dilution factor at Pensacola is 0.37 when calculated accurately from the full distribution of precipitation depths (Fig. S4) using Eq. (S7) versus 0.41 when calculated from the 
mean precipitation depth (Table 3) with the simple method of Eq. (S8). The simple method is similarly accurate at all other sites, so we use it because it facilitates error analysis.

The deposition ratio in Table 3 between sites $x$ and $y$ is $\widehat{D}_{x} / \widehat{D}_{y}$, where the numerator and denominator are from Eq. (S6) with values for their respective sites. The impact of a single variable on the deposition ratio is determined while holding all other variables equal in the numerator and denominator. The deposition ratio for baseline concentration alone is $\beta_{0, x} / \beta_{0, y}$; for total precipitation $p_{t, x} / p_{t, y}$; for characteristic dilution $\tilde{c}_{x} / \tilde{c}_{y}=\left(\tilde{p}_{x} / \tilde{p}_{y}\right)^{\beta_{1}}$; and for thunderstorm frequency $\left(1+f_{x} \beta_{2}\right) /\left(1+f_{y} \beta_{2}\right)$. The product of all components ratios equals $\widehat{D}_{x} / \widehat{D}_{y}$, so the decomposition allows us to see which factors are most important. Precipitation meteorology affects all factors except baseline concentration $\left(\beta_{0}\right)$, which is determined by emissions, chemistry, and transport. Uncertainties in each variable can be propagated to uncertainty in the deposition ratio using a first-order Taylor expansion of $\widehat{D}_{x} / \widehat{D}_{y}$ or the component formula with respect to all variables ${ }^{53}$.

\section{Precipitation climatology in Vermont and Florida}

During the years 2006-2011 summer Hg deposition was 1.43 times higher at site FL96 than VT99. Previous studies have reported ratios of 1.4-3.0 at other MDN sites in the Southeast and Northeast in summer ${ }^{2,3,8}$, so our result is at the lowest end of published results. Site FL96 received $500 \pm 60 \mathrm{~mm}$ total summer precipitation during the study years and site VT99 received $450 \pm 90 \mathrm{~mm}$. We consulted the NOAA Local Climatological Data (http://www.ncdc.noaa.gov/qclcd/QCLCD, accessed 25 March 2016) from the nearest airports (Table S1) to determine if these precipitation amounts are typical. At Pensacola airport $(20 \mathrm{~km}$ from FL96), the 20-year (1991-2010) mean summer precipitation was $130 \mathrm{~mm}$ greater than the 2006-2011 average. At Burlington airport (23 km from VT99), the 20-year mean summer precipitation was $30 \mathrm{~mm}$ less than the 2006-2011 average. As a result, the summer $\mathrm{Hg}$ deposition was likely anomalously small in Pensacola and anomalously large in Vermont during the study years.

As shown in Table 3, we estimate that the 2006-2011 precipitation totals alone explain a FL:VT deposition ratio of $1.11 \pm 0.26$, all else being equal. Using the 20 -year mean precipitation depths instead predicts a ratio of $1.50 \pm 0.35$. Eq. (2) would then predict a FL:VT deposition ratio of 2.40 \pm 0.65 under climate-normal precipitation amounts, which falls in the middle range of Southeast:Northeast deposition ratios that have been reported in the literature. 


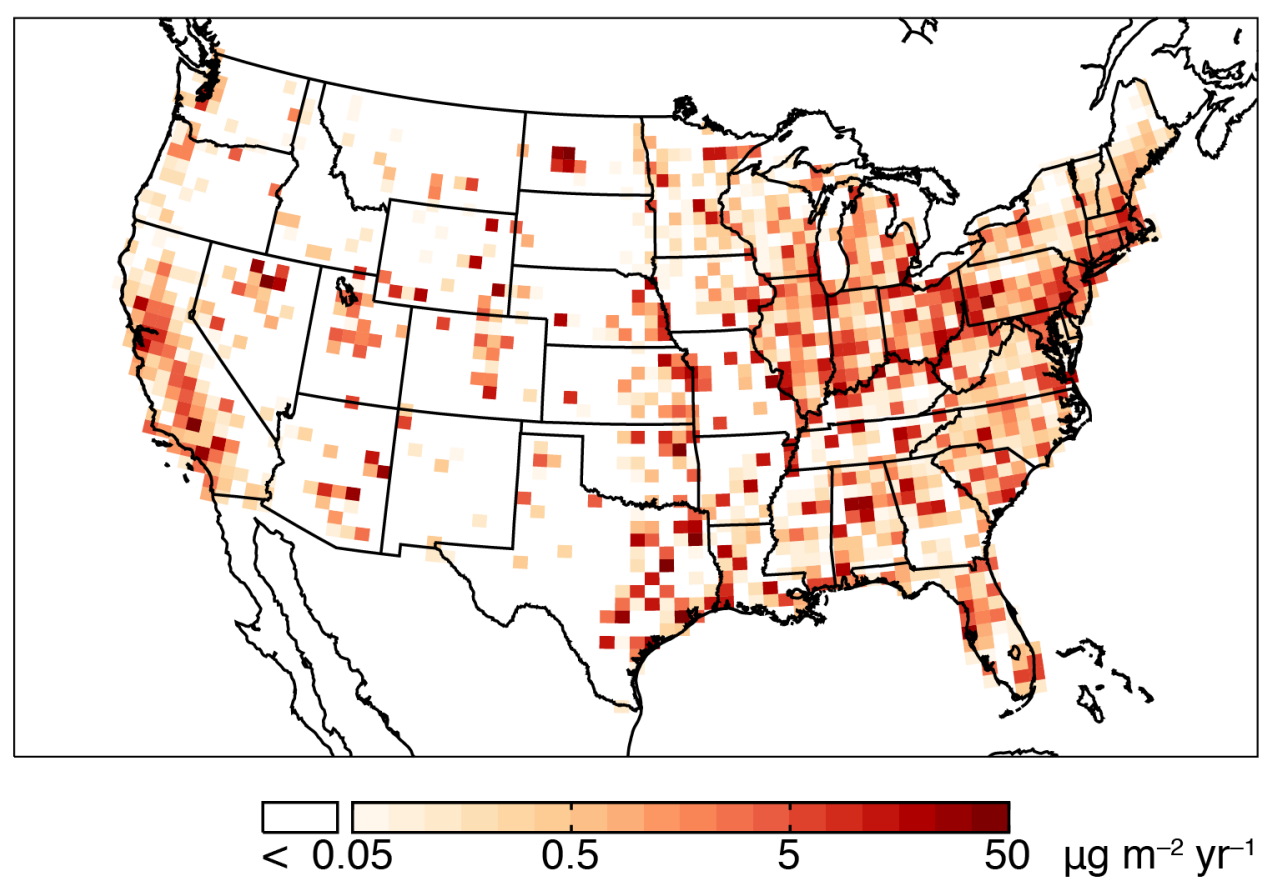

651

652

653

654

655
Figure S1. Anthropogenic emissions of gaseous and particle-bound $\mathrm{Hg}$ (II) in 2011. Data from the US Environmental Protection Agency's National Emission Inventory ${ }^{4}$. Note the logarithmic emission scale. 

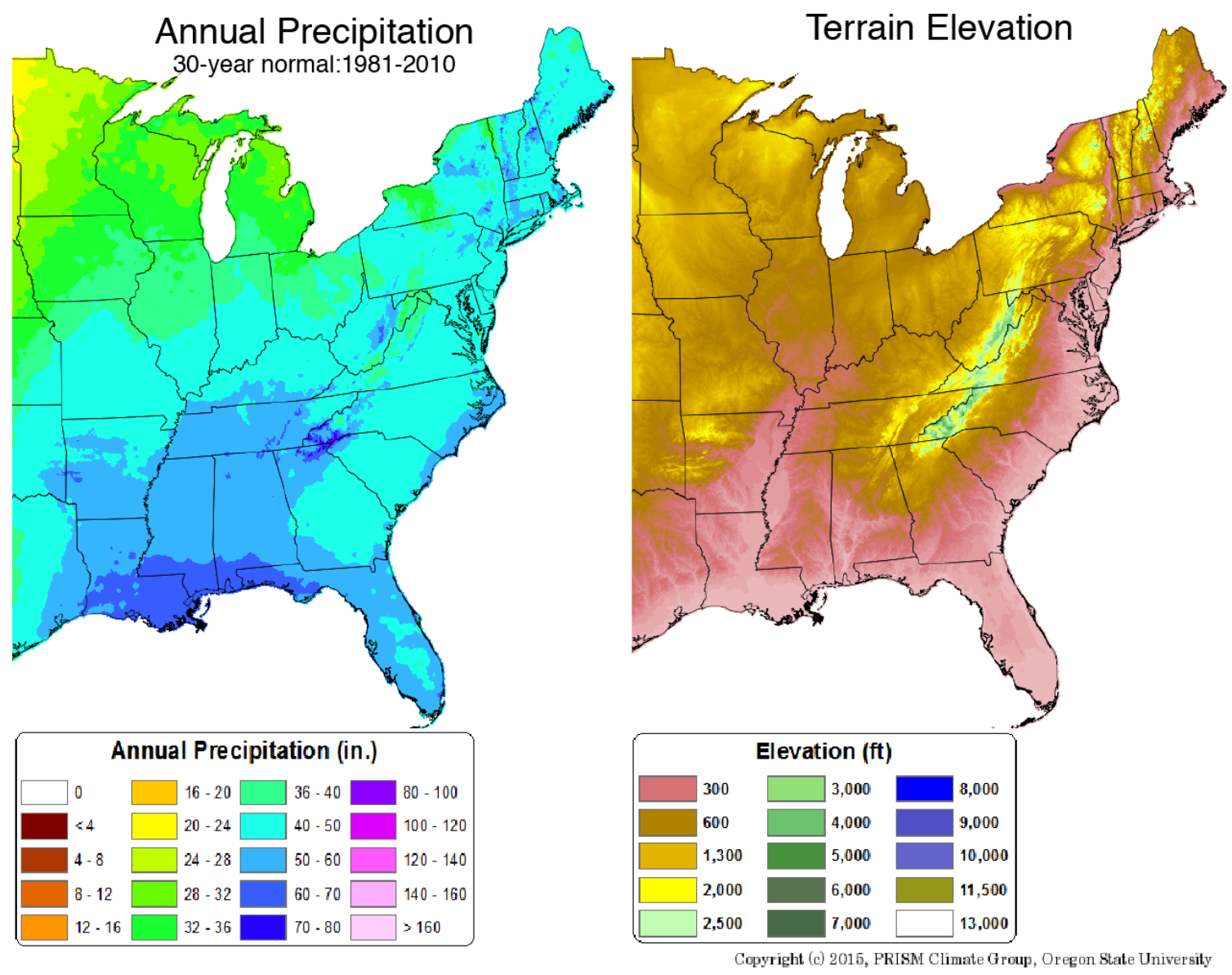

Figure S2. Annual precipitation and terrain elevation in the eastern United States. Copyright $($ C 659 2015, PRISM Climate Group, Oregon State University, http://prism.oregonstate.edu. Map created 6605 July 2016. (Reproduction and distribution permitted under PRISM Terms of Use) 


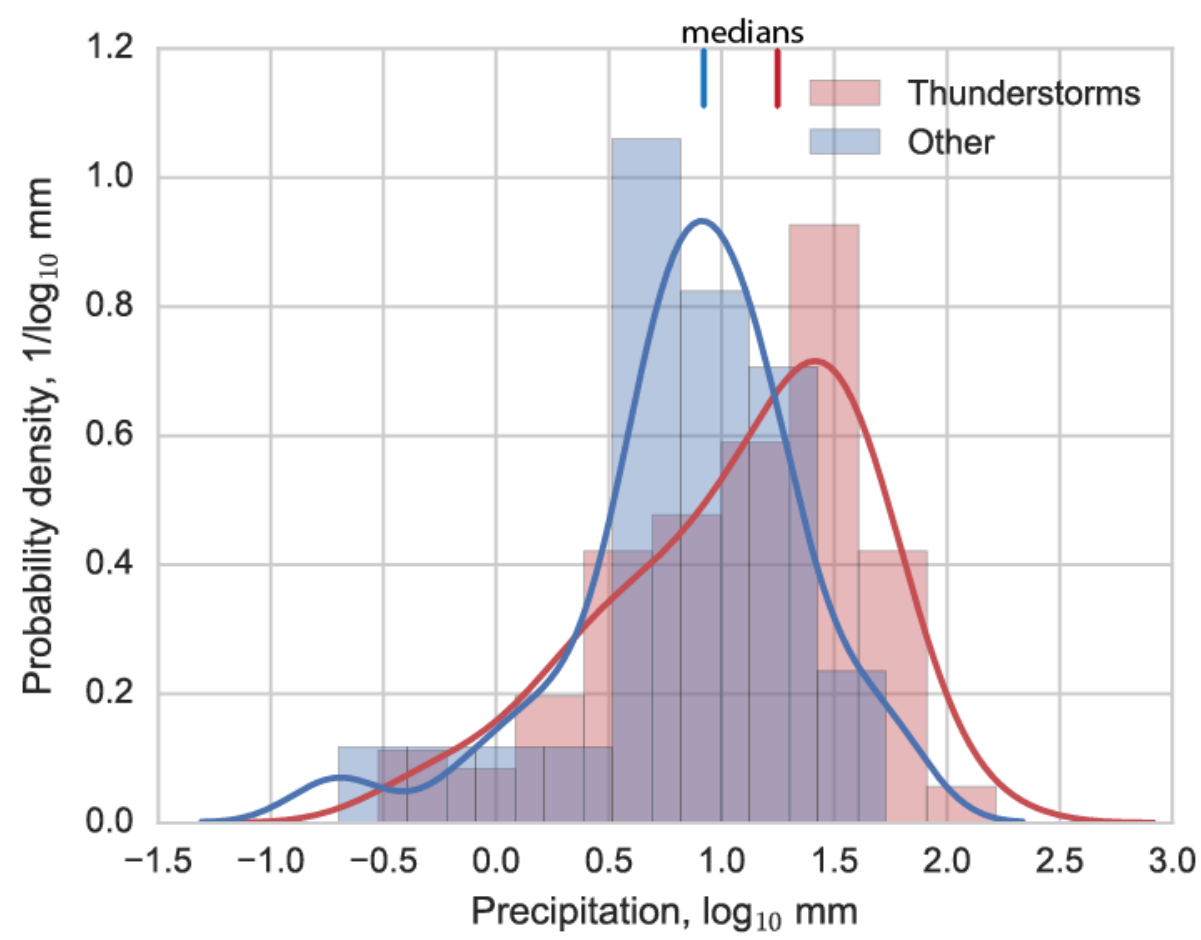

662

663

664

665

666

667

Figure S3. Distribution of summer precipitation depth at Pensacola, Florida (FL96) in 2006-2011, classified by storm type. Bars show histogram; lines show Gaussian kernel density estimate.

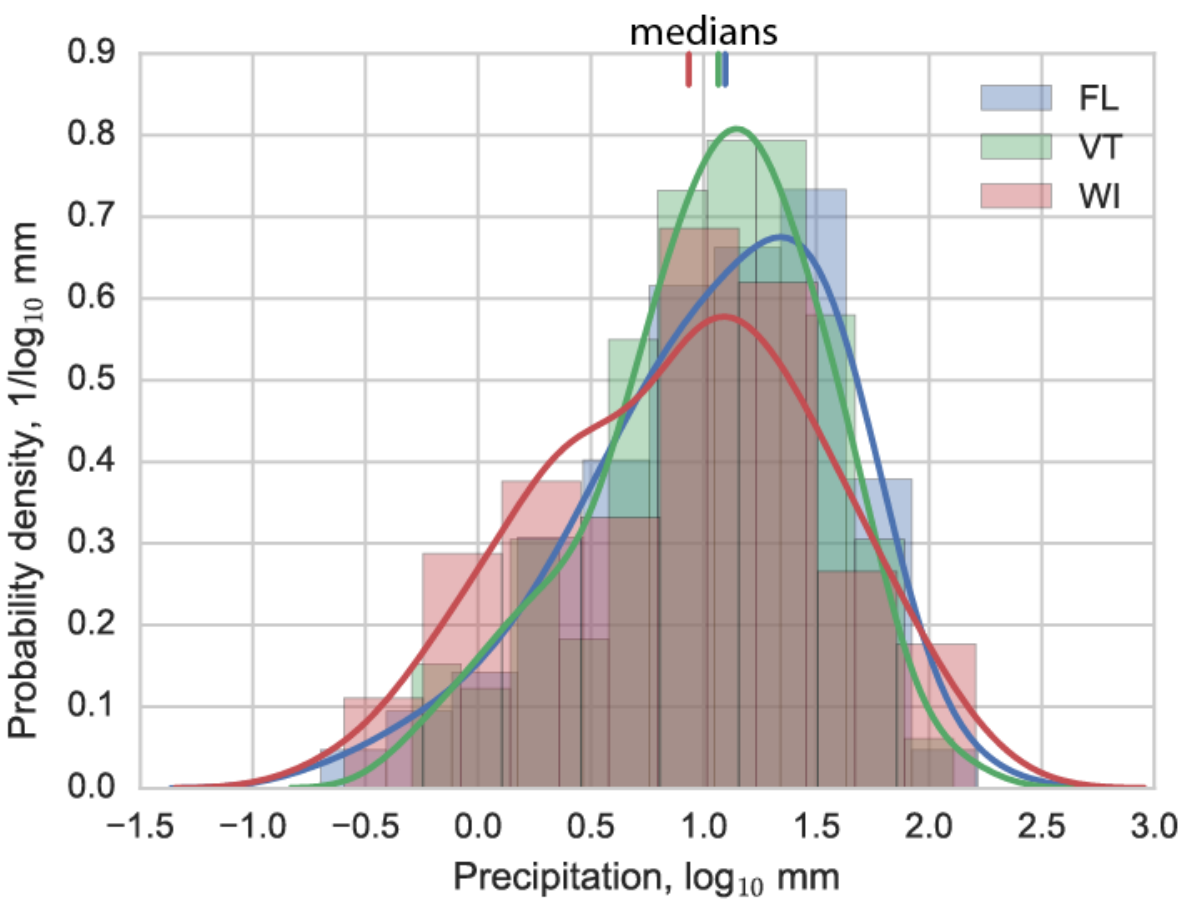

Figure S4. Distribution of summer precipitation depth in 2006-2011 classified by state. Bars show histogram; lines show Gaussian kernel density estimate. 
671 Table S1. Site locations and meteorological data sources

\begin{tabular}{|c|c|c|c|}
\hline Site (MDN code) & Coordinates & Airport $^{\mathrm{a}}$ (distance) & $\operatorname{Radar}^{\mathrm{a}}$ (distance) \\
\hline Ellyson Field, Pensacola, FL & $30.526^{\circ} \mathrm{N} 87.203^{\circ} \mathrm{W}$ & KPNS $(3.5 \mathrm{~km})$ & $\operatorname{KEVX}(124 \mathrm{~km})$ \\
\hline Pace site, Pensacola, FL & $30.602^{\circ} \mathrm{N} 87.191^{\circ} \mathrm{W}$ & KPNS (14 km) & $\operatorname{KEVX}(118 \mathrm{~km})$ \\
\hline Molino site, Pensacola, FL & $30.690^{\circ} \mathrm{N} 87.410^{\circ} \mathrm{W}$ & KPNS $(32 \mathrm{~km})$ & $\operatorname{KEVX}(143 \mathrm{~km})$ \\
\hline Outlying field, Pensacola, FL (FL96) & $30.550^{\circ} \mathrm{N} 87.374^{\circ} \mathrm{W}$ & KPNS (20 km) & KEVX $(138$ km) \\
\hline Yorkville, GA (GA40) & $33.931^{\circ} \mathrm{N} 85.046^{\circ} \mathrm{W}$ & $\operatorname{KVPC}(64 \mathrm{~km})$ & $\operatorname{KMXX}(174 \mathrm{~km})$ \\
\hline Devil's Lake, WI (WI31) & $43.435^{\circ} \mathrm{N} 89.680^{\circ} \mathrm{W}$ & KMSN (43 km) & KMKX (104 km) \\
\hline Underhill, VT (VT99) & $44.523^{\circ} \mathrm{N} 72.868^{\circ} \mathrm{W}$ & $\operatorname{KBTV}(23 \mathrm{~km})$ & KENX (225 km) \\
\hline
\end{tabular}

672

$673{ }^{a}$ Airports and radars are identified by their Automated Surface Observation System (ASOS) and 674 Weather Surveillance Radar-1988 Doppler (WSR-88D) codes, respectively. Chosen radar sites 675 can observe the upper troposphere over the rain collection site and may not be the closest radar 676 facility.

Table S2. Concentrations (mean \pm s.d.) of measured atmospheric mercury species during summer precipitation collection at FL96 ${ }^{\mathrm{a}}$

\begin{tabular}{|c|c|c|c|c|}
\hline Species ${ }^{b}$ & All & Thunderstorm & Non-thunderstorm & $P^{\mathrm{c}}$ \\
\hline $\mathrm{Hg}(0), \mathrm{ng} \mathrm{m}^{-3}$ & $1.25 \pm 0.11$ & $1.25 \pm 0.12$ & $1.23 \pm 0.08$ & 0.33 \\
\hline $\mathrm{GOM}, \mathrm{pg} \mathrm{m}^{-3}$ & $1.64 \pm 1.73$ & $1.63 \pm 1.80$ & $1.67 \pm 1.55$ & 0.93 \\
\hline Fine $\mathrm{PBM}, \mathrm{pg} \mathrm{m}^{-3}$ & $2.43 \pm 1.84$ & $2.29 \pm 1.85$ & $2.89 \pm 1.74$ & 0.09 \\
\hline Total $\mathrm{Hg}(\mathrm{II}), \mathrm{pg} \mathrm{m}^{-3}$ & $4.04 \pm 2.96$ & $3.87 \pm 3.03$ & $4.59 \pm 2.70$ & 0.21 \\
\hline
\end{tabular}

${ }^{a}$ Hourly data are averaged for each precipitation event; reported values are the mean and s.d. across events of the specified type.

${ }^{\mathrm{b}}$ Species as operationally defined by a Tekran $2537 / 1135 / 1130$ speciation unit ${ }^{16}$. GOM = gaseous oxidized mercury. Fine PBM = particle-bound mercury in PM2.5 size class.

${ }^{\mathrm{c}}$ Significance level of thunderstorm vs. non-thunderstorm differences (two-sided t-test with unequal variance).

694 
695 Table S3. Mean ( \pm s.d.) summer Hg deposition per rain event $\left(\mathrm{ng} \mathrm{m}^{-2}\right)$, excluding trace

696 precipitation

697

\begin{tabular}{llll} 
Site & All & Thunderstorm & Non-thunderstorm \\
\hline Florida (all) & $332 \pm 298$ & $362 \pm 310$ & $170 \pm 133$ \\
Florida (FL96) & $237 \pm 200$ & $260 \pm 210$ & $142 \pm 111$ \\
Georgia (GA40) & $204 \pm 199$ & $278 \pm 218$ & $108 \pm 116$ \\
Wisconsin (WI31) & $219 \pm 278$ & $281 \pm 308$ & $72 \pm 71$ \\
Vermont (VT99) & $159 \pm 194$ & $207 \pm 203$ & $122 \pm 180$
\end{tabular}

699

Table S4. Summer concentrations $\left(\mathrm{pg} \mathrm{m}^{-3}\right.$ ) of scavengable $\mathrm{Hg}(\mathrm{II})$ species at precipitation collection sites, from measurements and literature review

\begin{tabular}{|c|c|c|c|c|}
\hline Species ${ }^{\text {a }}$ & Florida (FL96) & Vermont (VT99) & Georgia (GA40) & Wisconsin (WI31) \\
\hline GOM & $1.6^{b}$ & $0.6,2^{(19,45)}$ & $5.1^{(46)}$ & $3.8^{(18)}$ \\
\hline Fine PBM & $2.4^{\mathrm{b}}$ & $2.9,3^{(19,45)}$ & $3.7^{(46)}$ & $6.4^{(18)}$ \\
\hline Total PBM (Fine + & 3.0-4.6 coarse at FL96 ${ }^{(26)}$ & $4.2^{\mathrm{c}}$ & $5.2^{\mathrm{c}}$ & $9.0^{\mathrm{c}}$ \\
\hline Coarse) & $\begin{array}{l}17 \pm 13 \text { at } \text { beach }^{(26)} \\
13 \pm 4 \text { at coastal site } \\
25 \pm 13 \text { at beach, marine flow }{ }^{(26)} \\
15 \pm 10 \text { at beach, mixed flow }\end{array}$ & & & \\
\hline $\mathrm{Hg}(\mathrm{II})=\mathrm{GOM}+$ Total & $10-20$ & 6.2 & 10.3 & 12.8 \\
\hline
\end{tabular}

\section{PBM}

$715{ }^{a}$ GOM $=$ gaseous oxidized mercury. Fine PBM = particle-bound mercury in PM2.5 size class.

716 Total PBM = particle-bound mercury of any size.

$717{ }^{\mathrm{b}}$ from measurements in Table S2.

$718{ }^{\mathrm{c}}$ assuming that coarse PBM is $\leq 40 \%$ of fine PBM at rural continental sites ${ }^{47,48}$.

720

721 